\title{
Tryptophan-Niacin Metabolism in Liver Cirrhosis Rat Caused by Carbon Tetrachloride
}

\author{
Yukari Egashira, * Ayano Isagawa, Tomoko Komine, \\ Etsuko Yamada, Takeo OHTA, Katsumi Shibata ${ }^{1}$ \\ and Hiroo SANADA \\ Department of Bioproduction Science, Faculty of Horticulture, \\ Chiba University, Matsudo 271-8510, Japan \\ ${ }^{1}$ Department of Life-Style Studies, School of Human Cultures, \\ The University of Shiga Prefecture, Hikone 522-8533, Japan
}

(Received March 8, 1999)

\begin{abstract}
Summary We investigated the change of tryptophan-niacin metabolism induced by carbon tetrachloride $\left(\mathrm{CCl}_{4}\right)$ in rats with liver cirrhosis. The rats were injected with $\mathrm{CCl}_{4}(0.5$ or $1 \mathrm{~mL}$ of $50 \%$ olive oil solution $/ \mathrm{kg}$ body weight) twice a week for 1 or 2 mo and given phenobarbital water simultaneously. The urinary excretions of nicotinamide (Nam) and its metabolites were assayed. As the result, the urinary excretion of Nam, $N^{1}$-methyl-4-pyridone-3-carboxamide (4-Py), $\mathrm{Nam}+N^{1}$-methylnicotinamide (MNA) $+N^{1}$-methyl-2-pyridone-5-carboxamide (2-Py) +4-Py was lower in the $\mathrm{CCl}_{4}$-treated groups than in the non-treated group (control) regardless of the experimental period ( $1 \mathrm{mo}$ and $2 \mathrm{mo}$ ) or dosing amount of $\mathrm{CCl}_{4}(0.5$ and $1 \mathrm{~mL})$. Moreover, we investigated which pathway of tryptophan-niacin metabolism was affected in $\mathrm{CCl}_{4}$-treated rat. As the result, the possibility that the $\mathrm{MNA} \rightarrow 4-\mathrm{Py}$ reaction is inhibited by $\mathrm{CCl}_{4}$ treatment was suggested in this experiment.
\end{abstract}

Key Words nicotinamide, tryptophan, rat, carbon tetrachloride, liver cirrhosis

It is well known that D-galactosamine induces hepatitis in rats $(I)$. We have reported that hepatic $\alpha$-amino- $\beta$-carboxymuconate- $\varepsilon$-semialdehyde decarboxylase (ACMSD) (EC 4.1.1.45) (Fig. 1) activity was suppressed and the urinary excretion of nicotinamide (Nam) and its metabolites increased in D-galactosamine-injected rats (2). On the other hand, it has been reported that the urinary excretion of $N^{1}$-methylnicotinamide (MNA), one of the final metabolites of niacin, increased in patients with cirrhosis of the liver (3). However, few investigations have been

* To whom correspondence should be addressed.

E-mail: egashira@midori.h.chiba-u.ac.jp 


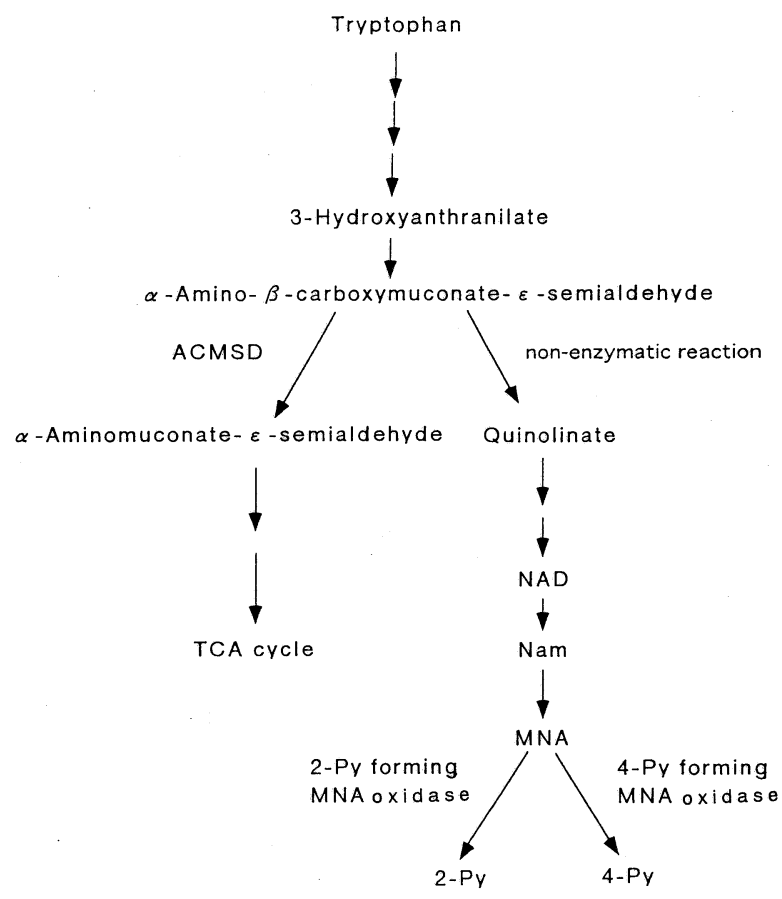

Fig. 1. Conversion of tryptophan to nicotinamide adenine dinucleotide. ACMSD: $\alpha$-amino- $\beta$-carboxymuconate- $\varepsilon$-semialdehyde decarboxylase.

performed on the effect of liver cirrhosis on other metabolites of niacin, such as $N^{1}$-methyl-4-pyridone-3-carboxamide (4-Py), or the tryptophan-niacin conversion ratio, in rats. The most abundant metabolite in rats is not MNA but 4-Py (4). The excretion of 4-Py amounts to about $80 \%$ of the total amount of urinary Nam and its metabolites (4). Therefore, it is important to measure 4-Py and to know the tryptophan-niacin conversion ratio in liver cirrhosis rat from the viewpoint of nutrition. It has long been known that cirrhosis of the liver can be produced in rats by dosing them with carbon tetrachloride $\left(\mathrm{CCl}_{4}\right)$ and phenobarbital simultaneously (5). We studied the effect of liver cirrhosis induced by $\mathrm{CCl}_{4}$ on the tryptophan-niacin metabolism in rats in association with the dosing amount and administration period of $\mathrm{CCl}_{4}$. Moreover, we investigated which pathways of tryptophan-niacin metabolism were affected in $\mathrm{CCl}_{4}$-treated rats. As a result, contrary to the result of galactosamine-induced liver injury, $\mathrm{CCl}_{4}$ treatment caused a decrease in the urinary excretion of Nam and its metabolites in rats.

\section{MATERIALS AND METHODS}

Chemicals. A transaminase assay kit, Iatrozyme TA-Lq, was obtained from Iatron Laboratories (Tokyo, Japan). $N^{1}$-methyl-2-pyridone-5-carboxamide (2-Py) 
and 4-Py were synthesized by the methods of Pullman and Colowick (6) and Shibata et al (7), respectively. Carbon tetrachloride and sodium phenobarbital were obtained from Wako Pure Chemicals (Osaka, Japan).

Animals and diets. The care and treatment of the rats were carried out according to the guidelines prescribed at our institution and the NIH guide for the care and use of laboratory animals (8).

Male rats of the Wistar strain, 4 wk, were obtained from CLEA Japan. The animals were housed in an air-conditioned room at $22 \pm 1{ }^{\circ} \mathrm{C}$ with 12 -h light and dark cycles. The rats were fed a commercial diet (CE-2, obtained from CLEA Japan) for $1 \mathrm{wk}$ to acclimatize them to the environment.

Exp. 1: The rats were divided into the following five groups $(n=6-8)$ : control (normal group), 1-mo; $\mathrm{CCl}_{4} 1 \mathrm{~mL}, 1$-mo; control, 2-mo; $\mathrm{CCl}_{4} 0.5 \mathrm{~mL}, 2-\mathrm{mo}$; and $\mathrm{CCl}_{4} 1 \mathrm{~mL}, 2-\mathrm{mo}$. The control group $(n=6)$ was injected subcutaneously with $0.5 \mathrm{~mL}$ olive oil $/ \mathrm{kg}$ body weight twice per week for 1 or 2 mo and drank water ad libitum. The $\mathrm{CCl}_{4}$-treated groups were injected with 0.5 or $1 \mathrm{~mL}$ of $50 \% \mathrm{CCl}_{4}$ in olive oil $(\mathrm{v} / \mathrm{v}) / \mathrm{kg}$ body weight twice per week for 1 or 2 mo. Sodium phenobarbital was dissolved in water at a concentration of $0.05 \%(\mathrm{w} / \mathrm{v})$. This was the only drinking water available to the $\mathrm{CCl}_{4}$-treated rats. The animals were fed the diets (casein $20 \%$, DL-methionine $0.15 \%, \alpha$-cornstarch $40 \%$, sucrose $25.15 \%$, mineral mixture (AIN-76 ratio) $3.5 \%$, vitamin mixture (AIN-76 ratio) $1 \%$, choline bitartrate $0.2 \%$, cellulose $5 \%$, corn oil $5 \%$ ) ad libitum for 1 or $2 \mathrm{mo}$. Then, the rats treated for $1 \mathrm{mo}$ were fed niacin-free diets (casein 20\%, DL-methionine $0.15 \%, \alpha$-cornstarch $40 \%$, sucrose $25.15 \%$, mineral mixture (AIN-76 ratio) 3.5\%, niacin-free vitamin mixture (AIN-76 ratio) $1 \%$, choline bitartrate $0.2 \%$, cellulose $5 \%$, corn oil $5 \%$ ) from the 30 th day to the 37 th day, and the rats treated for 2 mo were fed niacin-free diets from the 57 th day to the 64 th day to measure Nam and its metabolites. Urine was collected in flasks containing $1 \mathrm{M} \mathrm{HCl}(1 \mathrm{~mL} / 50 \mathrm{~mL}$ urine $)$ from $14: 00 \mathrm{~h}$ on the $35 \mathrm{th}$ day to the 37 th day for $48 \mathrm{~h}$ ( 1 mo treatment) or from the $62 \mathrm{nd}$ day to the $64 \mathrm{th}$ day $\left(2 \mathrm{mo}\right.$ treatment) of the experiment. The urine was stored at $-25^{\circ} \mathrm{C}$ until analysis for Nam and its metabolites. On the 37th or 64th day, the rats were sacrificed under anesthesia with sodium pentobarbital $(60 \mathrm{mg} / \mathrm{kg}$ body weight) at 14:00 h.

Exp. 2: The rats were divided into 2 groups: a control group and $\mathrm{CCl}_{4}$-treated group ( $n=4-6)$. The control group was injected subcutaneously with $0.5 \mathrm{~mL}$ olive oil/ $\mathrm{kg}$ body weight twice per week for $71 \mathrm{~d}$. The $\mathrm{CCl}_{4}$-treated group was injected with $1 \mathrm{~mL}$ of $50 \% \mathrm{CCl}_{4}$ in olive oil (v/v)/ $\mathrm{kg}$ body weight twice per week for $71 \mathrm{~d}$ and drank $0.05 \%(\mathrm{w} / \mathrm{v})$ phenobarbital water ad libitum. The rats were fed a commercial diet for $50 \mathrm{~d}$ and then fed a niacin-free diet, which was the same as Exp. 1, from the 50th day to the 71st day to measure Nam and its metabolites. On the 57 th day, urine was collected for $24 \mathrm{~h}$. On 61 st day, just after the rats were force-fed Nam $(100 \mathrm{mg} / \mathrm{rat})$ by stomach tube at $14: 00 \mathrm{~h}$, urine was collected. On the 64 th day, the rats were force-fed tryptophan $(100 \mathrm{mg} / \mathrm{rat})$ by stomach tube, and immediately following, urine was collected for $24 \mathrm{~h}$. On the 71 st day, the rats were 
sacrificed under anesthesia with sodium pentbarbital.

The activities of aspartate transaminase (GOT) (EC 2.6.1.1) and alanine transaminase (GPT) (EC 2.6.1.2) in the serum were determined by a clinical enzyme assay kit, Iatrozyme TA-Lq.

Measurement of urinary excretion of Nam and its metabolites. The urinary excretion of Nam, MNA, 2-Py and 4-Py was simultaneously measured by the method of Shibata et al $(7,9)$.

Statistical analysis. The significance of difference was determined by unpaired Student's $t$-test between 2 groups (Exp. 1, 1 mo treatment and Exp. 2), and the data of 3 groups (Exp. 1, 2 mo treatment) were analysis using ANOVA followed by Duncan's multiple-range test. All analyses were conducted using the Yukm Statistical Library (A.S.B., Tokyo).

\section{RESULTS}

\section{Experiment 1}

Change of body weight gain and transaminase activity. Table 1 shows the body weight gain and food intake of the experimental animals. In the groups treated for $1 \mathrm{mo}$, the body weight gain and food efficiency decreased in the $\mathrm{CCl}_{4}$ group as compared to the control group. But the food intake of the $\mathrm{CCl}_{4}$ group was not significantly different from the control group. In the groups treated for 2 mo, body weight gain and food efficiency decreased in the $\mathrm{CCl}_{4}$ groups in response to the amount of $\mathrm{CCl}_{4}$ administered.

Table 2 shows the serum transaminase activity of the experimental animals. In the groups treated for $1 \mathrm{mo}$, the activity of serum GPT was higher in the $\mathrm{CCl}_{4}$ group than in the control group. In the groups treated for $2 \mathrm{mo}$, the activities of GOT and GPT were higher in the $\mathrm{CCl}_{4}$ groups in response to the amount of $\mathrm{CCl}_{4}$ administered.

Urinary excretion of Nam and its metabolites. As shown in Fig. 2, the urinary excretion of Nam, MNA, 4-Py, and Nam + MNA + 2-Py + 4-Py was lower in the $\mathrm{CCl}_{4}$ group than in the control group treated for $1 \mathrm{mo}$. On the other hand, in the groups treated for $2 \mathrm{mo}$, Nam, 4-Py and Nam + MNA + 2-Py + 4-Py were decreased in the $\mathrm{CCl}_{4}$ group. This result shows that the decrease in urinary excretion of niacin metabolites is not related to the amount of $\mathrm{CCl}_{4}$ administered.

\section{Experiment 2}

Change of body weight gain and transaminase activity. Table 3 shows the body weight gain and the weight of organs of the experiment animals. The weight gain and food intake in the $\mathrm{CCl}_{4}$ group were not significantly different from the control group. But the relative liver weight and relative kidney weight were higher in the $\mathrm{CCl}_{4}$ group than in the control group.

Figure 3 shows the serum transaminase activity. The activities of serum GOT and GPT were higher in the $\mathrm{CCl}_{4}$ group than in the control group. 


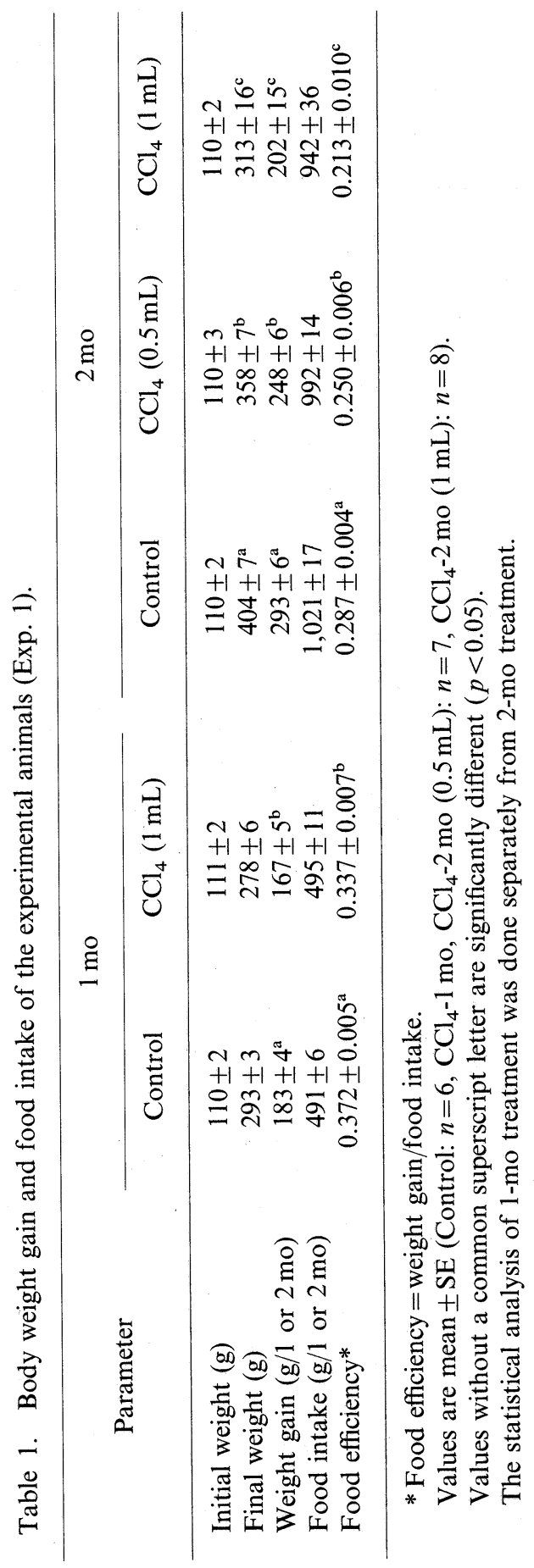


Table 2. Serum transaminase (GOT, GPT) activity of the experimental animals (Exp. 1).

\begin{tabular}{ccccccc}
\hline \multirow{2}{*}{ Parameter } & \multicolumn{2}{c}{$1 \mathrm{mo}$} & & \multicolumn{2}{c}{$2 \mathrm{mo}$} \\
\cline { 2 - 3 } \cline { 5 - 7 } \cline { 5 - 7 } & Control & $\mathrm{CCl}_{4}(1 \mathrm{~mL})$ & & Control & $\mathrm{CCl}_{4}(0.5 \mathrm{~mL})$ & $\mathrm{CCl}_{4}(1 \mathrm{~mL})$ \\
\hline GOT (K.U.*) & $75.3 \pm 6.3$ & $130 \pm 17$ & & $64.4 \pm 0.9^{\mathrm{c}}$ & $137 \pm 37^{\mathrm{b}}$ & $639 \pm 233^{\mathrm{a}}$ \\
GPT (K.U.) & $30.9 \pm 0.9^{\mathrm{b}}$ & $88.0 \pm 22.4^{\mathrm{a}}$ & & $28.3 \pm 1.4^{\mathrm{c}}$ & $128 \pm 60^{\mathrm{b}}$ & $508 \pm 184^{\mathrm{a}}$ \\
\hline
\end{tabular}

* K.U.: Karmen unit.

Values are mean $\pm \mathrm{SE}$ (Control: $n=6, \mathrm{CCl}_{4}-1 \mathrm{mo}, \mathrm{CCl}_{4}-2 \mathrm{mo} \quad(0.5 \mathrm{~mL}): n=7$, $\left.\mathrm{CCl}_{4}-2 \mathrm{mo}(1 \mathrm{~mL}): n=8\right)$.

Values without a common superscript letter are significantly different $(p<0.05)$.

The statistical analysis of 1-mo treatment was done separately from 2-mo treatment.

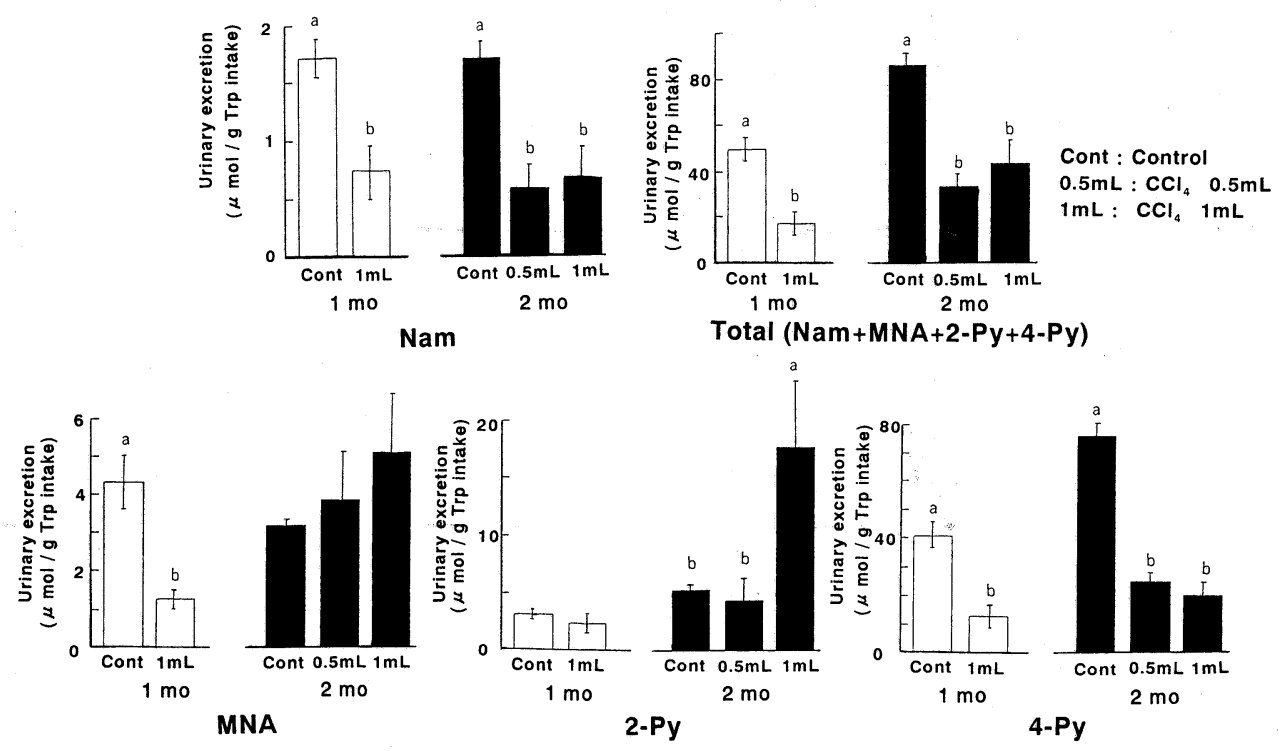

Fig. 2. Urinary excretion of nicotinamide and its metabolites from the experimental animals (Exp. 1). The rats were injected with carbon tetrachloride $\left(\mathrm{CCl}_{4}\right)(0.5$ or $1 \mathrm{~mL}$ of $50 \%$ olive oil solution/kg body weight) twice a week for 1 or $2 \mathrm{mo}$. Similarly the control group was injected with $0.5 \mathrm{~mL}$ olive oil $/ \mathrm{kg}$ body weight. The urinary excretions of nicotinamide and its metabolites were assayed as described in Materials and Methods. Each bar represents mean \pm SE of 6-8 rats. Values without a common superscript letter are significantly different $(p<0.05)$. The statistical analysis of 1-mo treatment was done separately from 2-mo treatment. 
Table 3. Body weight gain, food intake and weight of organs of the experimental animals (Exp. 2).

\begin{tabular}{lcc}
\hline \multicolumn{1}{c}{ Parameter } & Control & $\mathrm{CCl}_{4}$ \\
\hline Initial weight (g) (at day 0) & $127 \pm 2$ & $127 \pm 2$ \\
Initial weight (g) (at 50th day) (start niacin-free diet) & $396 \pm 11$ & $270 \pm 22^{*}$ \\
Weight gain (g/21 d) (from 50th day to 71st day) & $44 \pm 4$ & $54 \pm 16$ \\
Food intake (g/21 d) (from 50th day to 71st day) & $421 \pm 13$ & $356 \pm 57$ \\
Eviscerated carcass weight (g) & $340 \pm 11$ & $224 \pm 24^{*}$ \\
Liver weight (g) & $17.4 \pm 0.8$ & $15.2 \pm 1.2$ \\
Relative liver weight (g/100 g eviscerated carcass weight) & $5.1 \pm 0.1$ & $7.1 \pm 1.0^{*}$ \\
Kidney weight (g) & $2.7 \pm 0.1$ & $2.9 \pm 0.2$ \\
Relative kidney weight (g/100 geviscerated carcass weight) & $0.8 \pm 0.0$ & $1.3 \pm 0.1^{*}$
\end{tabular}

Values are means $\pm \mathrm{SE}$ (Control: $n=6, \mathrm{CCl}_{4}: n=4$ ).

* Significantly different from the control group by Student's $t$-test $(p<0.05)$.

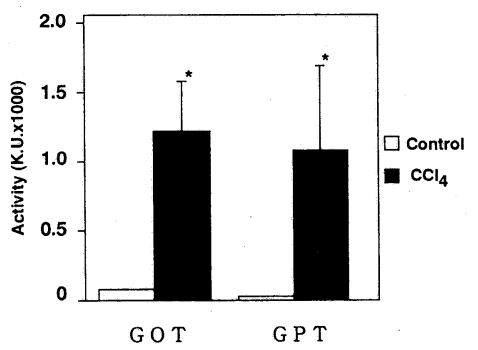

Fig. 3. Serum transaminase activities (Exp. 2). The rats were injected with carbon tetrachloride $\left(\mathrm{CCl}_{4}\right)(1 \mathrm{~mL}$ of $50 \%$ olive oil solution $/ \mathrm{kg}$ body weight) twice a week for $2 \mathrm{mo}$. Similarly, the control group was injected with $0.5 \mathrm{~mL}$ olive oil $/ \mathrm{kg}$ body weight. Transaminase activity was assayed as described in Materials and Methods. Each bar represents mean $\pm \mathrm{SE}$ of $4-6$ rats. * Significantly different from the control group $(p<0.05)$.

Urinary excretion of Nam and its metabolites. Figure 4 shows the urinary excretion of Nam and its metabolites. In this experiment, which pathways of tryptophan-niacin were affected in $\mathrm{CCl}_{4}$-treated rats was investigated, so rats were force-fed a large amount of tryptophan or Nam, substrates of intermediary metabolites. 2-Py was higher and 4-Py and total metabolites were lower in the $\mathrm{CCl}_{4}$ group than in the control group. When the rats were fed a large amount of tryptophan (Fig. 4b), the result of urinary excretion of Nam and its metabolites was almost the same as that of no treatment (Fig. 4a). When treated with a large amount of Nam, Nam, 2-Py and total metabolites were higher and 4-Py was lower in the $\mathrm{CCl}_{4}$ group than in the control group. 

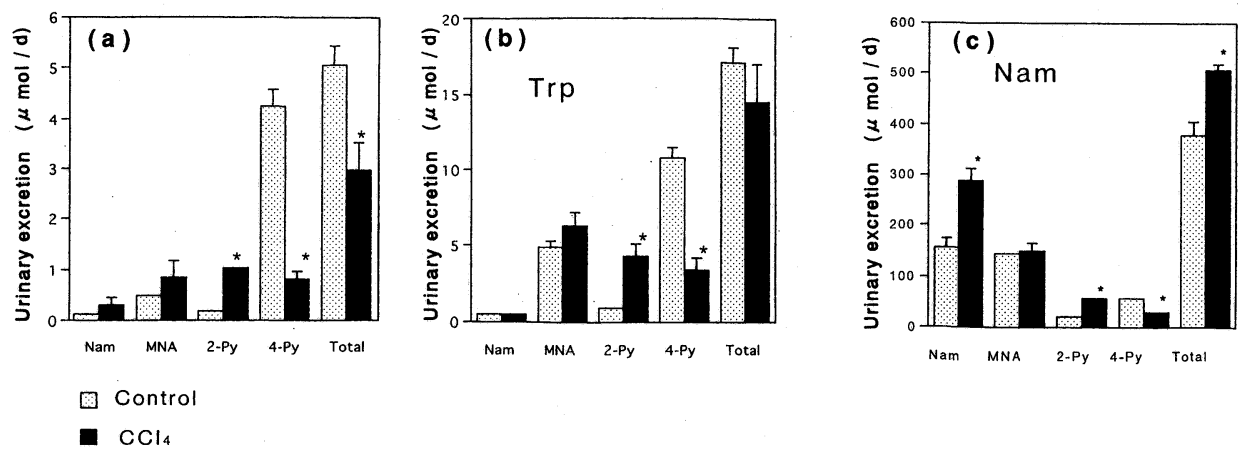

Fig. 4. Urinary excretion of nicotinamide and its metabolites from the experimental animals (Exp. 2). The rats were injected with carbon tetrachloride $\left(\mathrm{CCl}_{4}\right)(1 \mathrm{~mL}$ of $50 \%$ olive oil solution $/ \mathrm{kg}$ body weight) twice a week for $2 \mathrm{mo}$. Similarly, the control group was injected with $0.5 \mathrm{~mL}$ olive oil $/ \mathrm{kg}$ body weight. (a) No treatment. (b) The rats were fed tryptophan $(100 \mathrm{mg} / \mathrm{rat})$ by stomach tube before urine was collected. (c) The rats were fed Nam $(100 \mathrm{mg} / \mathrm{rat})$ by stomach tube before urine was collected. Each bar represents mean \pm SE of 4-6 rats. * Significantly different from the control group $(p<0.05)$.

\section{DISCUSSION}

It is well known that the long-term administration of $\mathrm{CCl}_{4}$ causes liver cirrhosis in rats $(10) . \mathrm{CCl}_{4}$ is metabolized to trichloromethyl radical in the cytochrome P-450 system. This radical attacks the cell membrane leading to lipid peroxidation, necrosis of centrilobular cells, disruption of endoplasmic reticulum and the failure of energy production through glycolysis by the mitochondria (11-14). On the other hand, the dosing of phenobarbital in drinking water causes a steady and prolonged rise in the amount of cytochrome $\mathrm{P}-450$ in the rat liver. $\mathrm{CCl}_{4}$ is metabolized in the liver into a toxic substance by a microsomal P-450 is equivalent, to an increase in the dose of $\mathrm{CCl}_{4}$ toxin (5).

In this experiment (Exp. 1), the tryptophan-niacin conversion ratio in $\mathrm{CCl}_{4}$ treated rats was significantly decreased (Fig. 2). The urinary excretion of Nam and its metabolites in cirrhosis of liver did not reflect the dose amount of $\mathrm{CCl}_{4}$ or the period of $\mathrm{CCl}_{4}$ administration. However, it becomes clear that the niacin requirement is higher for rats with hepatic cirrhosis than those with normal conditions. In normal rats, the excretion of 4-Py amounts to about $80 \%$ of the total amount of urinary Nam and its metabolites (4), so 4-Py dominates the tryptophan-niacin conversion ratio. 4-Py-forming MNA oxidase activity might be suppressed by $\mathrm{CCl}_{4}$ since, in the 2 mo treatment, the value of $(2-\mathrm{Py}+4-\mathrm{Py}) / \mathrm{MNA}$ was observed to be different between the control and $\mathrm{CCl}_{4}$ groups (Cont, 25.4; $\left.\mathrm{CCl}_{4}-0.5 \mathrm{~mL}, 7.6 ; \mathrm{CCl}_{4}-1 \mathrm{~mL}, 7.4\right)$. In groups treated for $2 \mathrm{mo}$, the urinary excretion of 2-Py was increased more in the $\mathrm{CCl}_{4}-1 \mathrm{~mL}$ group than in the $\mathrm{CCl}_{4}-0.5 \mathrm{~mL}$ group. 4-Py-forming MNA oxidase activity might be strongly suppressed in the $\mathrm{CCl}_{4}-1 \mathrm{~mL}$ 
group, and MNA may relatively accumulate or 2-Py-forming MNA oxidase might work priority and 2-Py in the urine may be increase in the $\mathrm{CCl}_{4}-1 \mathrm{~mL}$ group. In comparing $1 \mathrm{mo}$ and 2 mo groups, although the reason why the urinary excretion of MNA in the groups treated for $1 \mathrm{mo}(1 \mathrm{~mL})$ was greatly lower than that in the groups treated for $2 \mathrm{mo}(1 \mathrm{~mL})$ is not clear, 4-Py-forming MNA oxidase in the groups treated for 2 mo might be suppressed more than that in the groups treated for $1 \mathrm{mo}$. The values of (2-Py +4-Py)/MNA were 11.4 and 7.4 for the groups treated $1 \mathrm{mo}(1 \mathrm{~mL})$ and $2 \mathrm{mo}(1 \mathrm{~mL})$, respectively. Therefore, MNA may accumulate with treatment for $2 \mathrm{mo}$.

The pattern of urinary excretion of Nam and its metabolites in Exp. 2 (Fig. 4a) was the same as Exp. 1 (Fig. 2). With the addition of tryptophan treatment (Exp. 2, Fig. 4b), a large amount of the substrate, tryptophan, enters the body temporarily, so a non-enzymatic reaction of $\alpha$-amino- $\beta$-carboxymuconate- $\varepsilon$-semialdehyde (ACMS) (ACMS $\rightarrow$ quinolinate $\rightarrow \rightarrow$ NAD) may proceed, and the rate of entry to the NAD pathway may be increased. Furthermore, the total urinary excretion of niacin metabolite in the $\mathrm{CCl}_{4}$ group did not decrease so much. When treated with a large amount of Nam (Exp. 2, Fig. 4c), the pattern of urinary excretion of niacin metabolite was different from Exp. 1 (Fig. 2) and the tryptophan-treated groups (Fig. 4b) since this reaction did not pass through the ACMSD. Therefore, the total amount of urinary excretion of niacin metabolites increased. MNA/total and Nam/total in the Nam-treated groups increased since a large amount of Nam entered the body at one time and it could not be absorbed and excreted in the urine or it may be hard to initiate the reaction MNA $\rightarrow 2 \mathrm{Py}$ or MNA $\rightarrow$ 4-Py; so MNA may accumulate. In this study, whether rats were administered a large amount of tryptophan or Nam, one of the results was the same; that is, 2-Py increased and 4-Py decreased in the $\mathrm{CCl}_{4}$ groups as compared to the control groups. Therefore, the reaction MNA $\rightarrow 4-\mathrm{Py}$ was considered to be suppressed and MNA $\rightarrow$ 2-Py promoted; thus, 2-Py in the $\mathrm{CCl}_{4}$ group may be increased.

Egashira et al reported that the tryptophan-niacin conversion ratio increased after an injection of D-galactosamine induced liver injury (2). An injection of D-galactosamine caused a decrease in liver ACMSD activity and liver tryptophan2,3-dioxygenase activity (2). Contrary to the results of D-galactosamine-induced liver injury, $\mathrm{CCl}_{4}$ treatment caused a decrease in the urinary excretion of Nam and its metabolite. Hepatic ACMSD plays a key role in regulating NAD biosynthesis from tryptophan (Fig. 1) $(15,16)$. If ACMSD activity is high enough, most tryptophan is metabolized to enter the glutarate pathway. However, if the activity is low, tryptophan is metabolized to enter the NAD pathway. Therefore, tryptophan niacin conversion is increased. In this study, the liver and kidney ACMSD activities of rats injected with $\mathrm{CCl}_{4}-1 \mathrm{~mL}$ for 2 mo increased significantly as compared to the control (liver 3-fold increase, kidney 1.3 -fold increase over control, data not shown). Therefore, the difference in the tryptophan-niacin conversion ratio between rats treated with $\mathrm{D}$-galactosamine and rats treated with 
$\mathrm{CCl}_{4}$ is considered to be attributable to increased ACMSD activity. Another possibility is that indolamine-2,3-dioxygenase might be related to these phenomena because one of the mechanisms for D-galactosamine hepatotoxicity and $\mathrm{CCl}_{4}$ hepatotoxicity is that kupffer cells are believed to participant $(17,18)$. In immune stimulation or activation, for example, lipopolysaccharide or interferon- $\gamma$ caused an increase in indolamine-2,3-dioxygenase activity in the systemic tissue and increased quinolinic acid concentration, but hepatic tryptophan-2,3-dioxygenase activity was either reduced or unaffected (19-21). D-Galactosamine induced acute liver injury ( $24 \mathrm{~h}$ after D-galactosamine administration), and in this study, $\mathrm{CCl}_{4}$ induced chronic liver injury ( 1 or 2 mo treatment). Therefore, immune response or tolerance might participate in the above-mentioned phenomena.

In this study, it becomes clear that the pathway from tryptophan to Nam was affected in the $\mathrm{CCl}_{4}$ groups and the urinary excretion of niacin metabolites in the $\mathrm{CCl}_{4}$-treated groups decreased; that is, the tryptophan-niacin conversion ratio was decreased. Moreover, under the Nam pathway, the possibility that the MNA $\rightarrow$ 4-Py reaction is suppressed by $\mathrm{CCl}_{4}$ treatment was suggested.

\section{REFERENCES}

1) Keppler D, Lesch R, Reutter W, Decker K. 1968. Experimental hepatitis induced by D-galactosamine. Exp Mol Pathol 9: 279-290.

2) Egashira Y, Komine T, Ohta T, Shibata K, Sanada H. 1997. Change of tryptophan-niacin metabolism in D-galactosamine-induced liver injury in rat. $J$ Nutr Sci Vitaminol 43: 233-239.

3) Gabuzda GJ, Davidson CS. 1962. Tryptophan and nicotinic acid metabolism in patient with cirrhosis of the liver. Am J Clin Nutr 11: 502-508.

4) Shibata K. 1988. Micro-determination of nicotinamide and its metabolites by high-performance liquid chromatography. Vitamins (Japan) 62: 225-233 (in Japanese).

5) McLean EK, McLean AEM, Sutton PM. 1969. Instant cirrhosis-An improved method for producing cirrhosis of the liver in rats by simultaneous administration of carbon tetrachloride and phenobarbitone. Br J Exp Pathol 50: 502-506.

6) Pullman ME, Colowick SP. 1954. Preparation of 2- and 6-pyridones of $\mathrm{N}$ methylnicitinamide. $J$ Biol Chem 206: 121-127.

7) Shibata K, Kawada T, Iwai K. 1988. Simultaneous microdetermination of nicotinamide and its major metabolites, $N^{1}$-methyl-2-pyridone-5-carboxamide and $N^{1}$-methyl-4pyridone-3-carboxamide, by high-performance liquid chromatography. $J$ Chromatogr 424: $23-28$.

8) National Research Council. 1985. Guide for the care and use of laboratory animals. NIH Publication No. 85-23 (rev.), U.S. Government Printing Office, Washington DC.

9) Shibata K. 1987. Ultramicro-determination of $N^{1}$-methyl-nicotinamide in urine by high-performance liquid chromatography. Vitamins (Japan) 61: 599-604 (in Japanese).

10) Recknagel RO. 1967. Carbon tetrachloride hepatotoxicity. Pharm Rev 19: 145-208.

11) Recknagel RO, Glende EA, Dolak JA, Waller RL. 1989. Mechanisms of carbon tetrachloride toxicity. Pharmacol Ther 43: 139-154.

12) Bruckner JV, Mackenzie WF, Muralidhara S, Luthra R, Kyle GM, Acosta D. 1986. Oral toxicity of carbon tetrachloride: acute, subacute, and subchronic studies in rats. 
Fundam Appl Toxicol 6: 16-34.

13) Shiratori Y, Ichida T, Kawase T, Wisse E. 1986. Effect of acetaldehyde on collagen synthesis by fat-storing cells isolated from rats treated with carbon tetrachloride. Liver 6: $246-251$.

14) Hernandez-Munoz R, Diaz-Munoz M, Chagoya de Sanchez V. 1992. Effects of adenosine administration on the function and membrane composition of liver mitochondria in carbon tetrachloride-induced cirrhosis. Arch Biochem Biophys 294: $160-167$.

15) Nishizuka Y, Hayaishi O. 1963. Studies on the biosynthesis of nicotinamide adenine dinucleotide. I. Enzymatic synthesis of niacin ribonucleotides from 3-hydroxyanthranilic acid in mammalian tissue. $J$ Biol Chem 238: 3369-3377.

16) Ikeda M, Tsuji H, Nakamura S, Ichiyama A, Nishizuka Y, Hayaishi O. 1965. Studies on the biosynthesis of nicotinamide adenine dinucleotide. J Biol Chem 240: 1395-1401.

17) Stachlewitz RF, Seabra V, Bradford B, Bradham CA, Rusyn I, Germolec D, Thurman RG. 1999. Glycine and uridine prevent D-galactosamine hepatotoxicity in the rat: Role of kupffer cells. Hepatology 29: 737-745.

18) Edwards MJ, Keller BJ, Kauffman FC, Thurman RG. 1993. The involvement of kupffer cells in carbon tetrachloride toxicity. Toxicol Appl Pharmacol 119: 275-279.

19) Saito K, Markey SP, Heyes MP. 1992. Effects of immune activation on quinolinic acid and neuroactive kynurenines in the mouse. Neuroscience 51: 25-39.

20) Heyes MP, Saito K, Major EO, Milstien S, Markey SP, Vickers JH. 1993. A mechanism of quinolinic acid formation by brain in inflammatory neurological disease. Brain 116 : $1425-1450$.

21) Saito K, Crowley JS, Markey SP, Heyes MP. 1993. A mechanism for increased quinolinic acid formation following acute systemic immune stimulation. $J$ Biol Chem 268 : 15496-15503. 